\title{
A Facile Synthetic Method for Conversion of Chlorophyll-a to Bacteriochlorophyll-c
}

Shin-ichi Sasaki, Tadashi Mizoguchi, and Hitoshi Tamiaki*

* To whom correspondence should be addressed.

Department of Bioscience and Biotechnology, Faculty of Science and Engineering, Ritsumeikan University, Kusatsu, Shiga 525-8577, Japan.

Fax: +81-77-561-2659, Tel: +81-77-566-1111, e-mail: tamiaki@se.ritsumei.ac.jp.

\section{List of contents}

Figures S1-S3

Figures S4-S6
${ }^{1} \mathrm{H}-\mathrm{NMR}$ spectra of $\mathbf{6 R}, \mathbf{6 S}$ and $\mathbf{7 R}$ in $\mathrm{CDCl}_{3}$.

${ }^{13} \mathrm{C}$-NMR spectra of $\mathbf{6 R}, \mathbf{6 S}$ and $\mathbf{7 R}$ in $\mathrm{CDCl}_{3}$.
S2-S4

S5-S7 

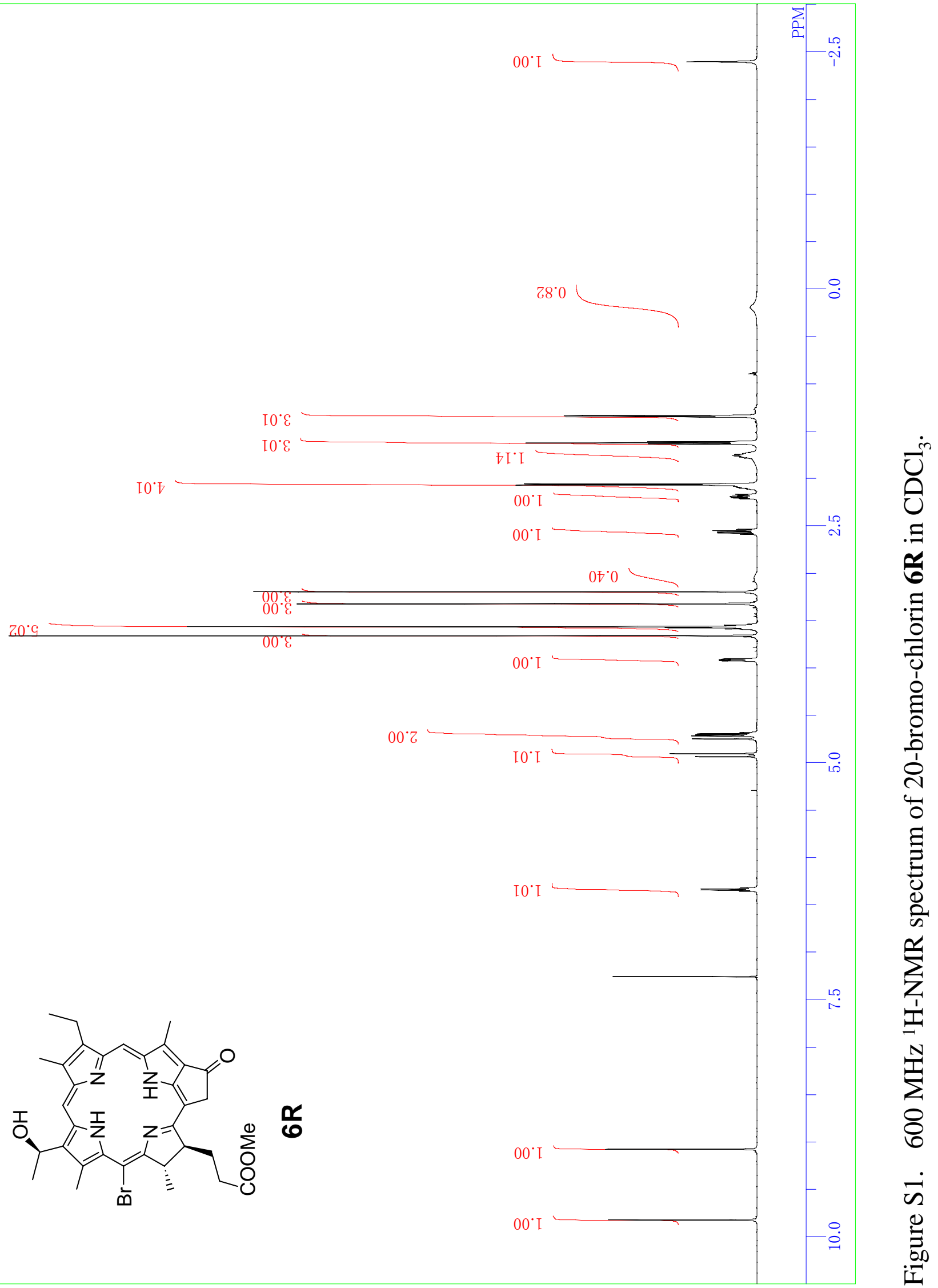

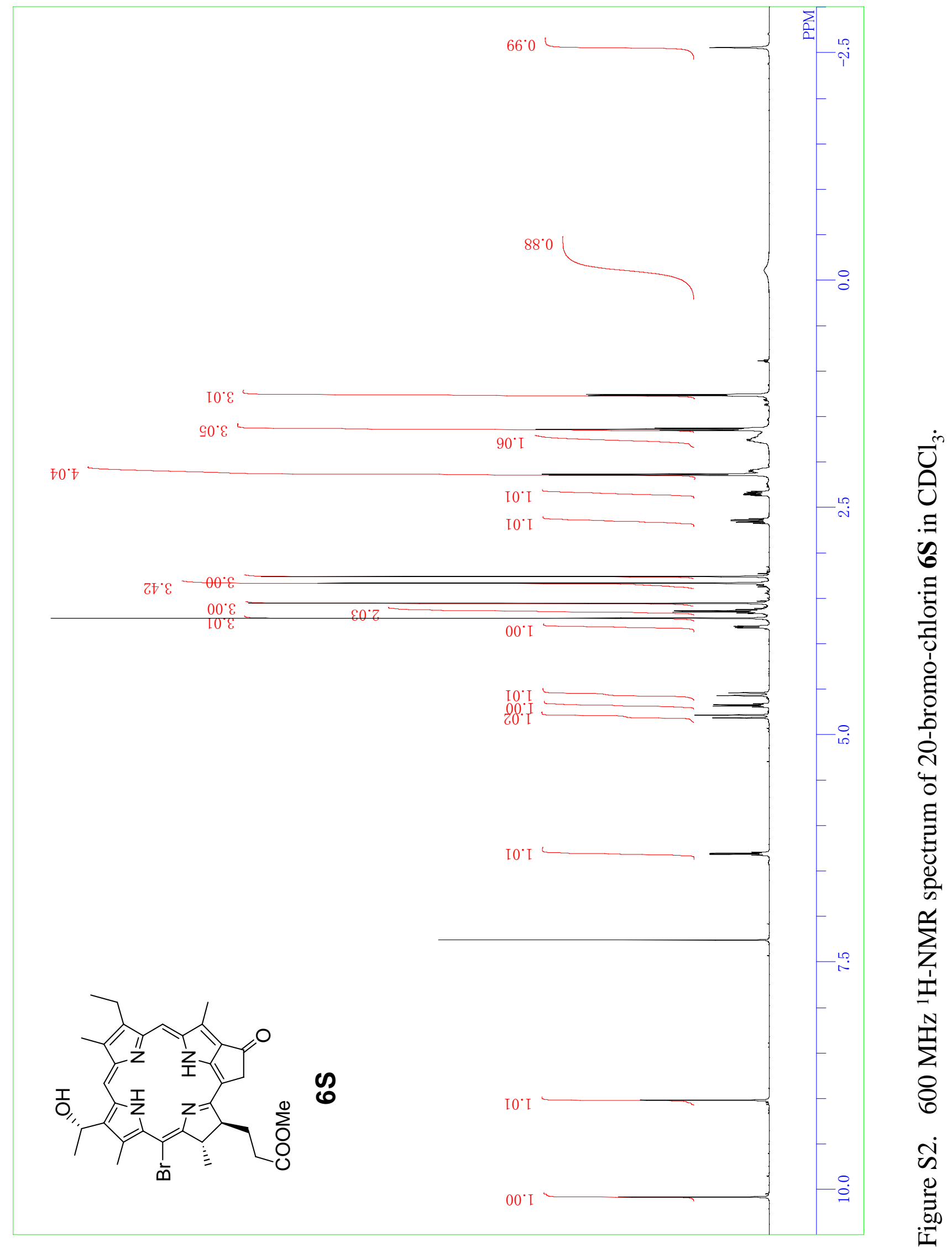

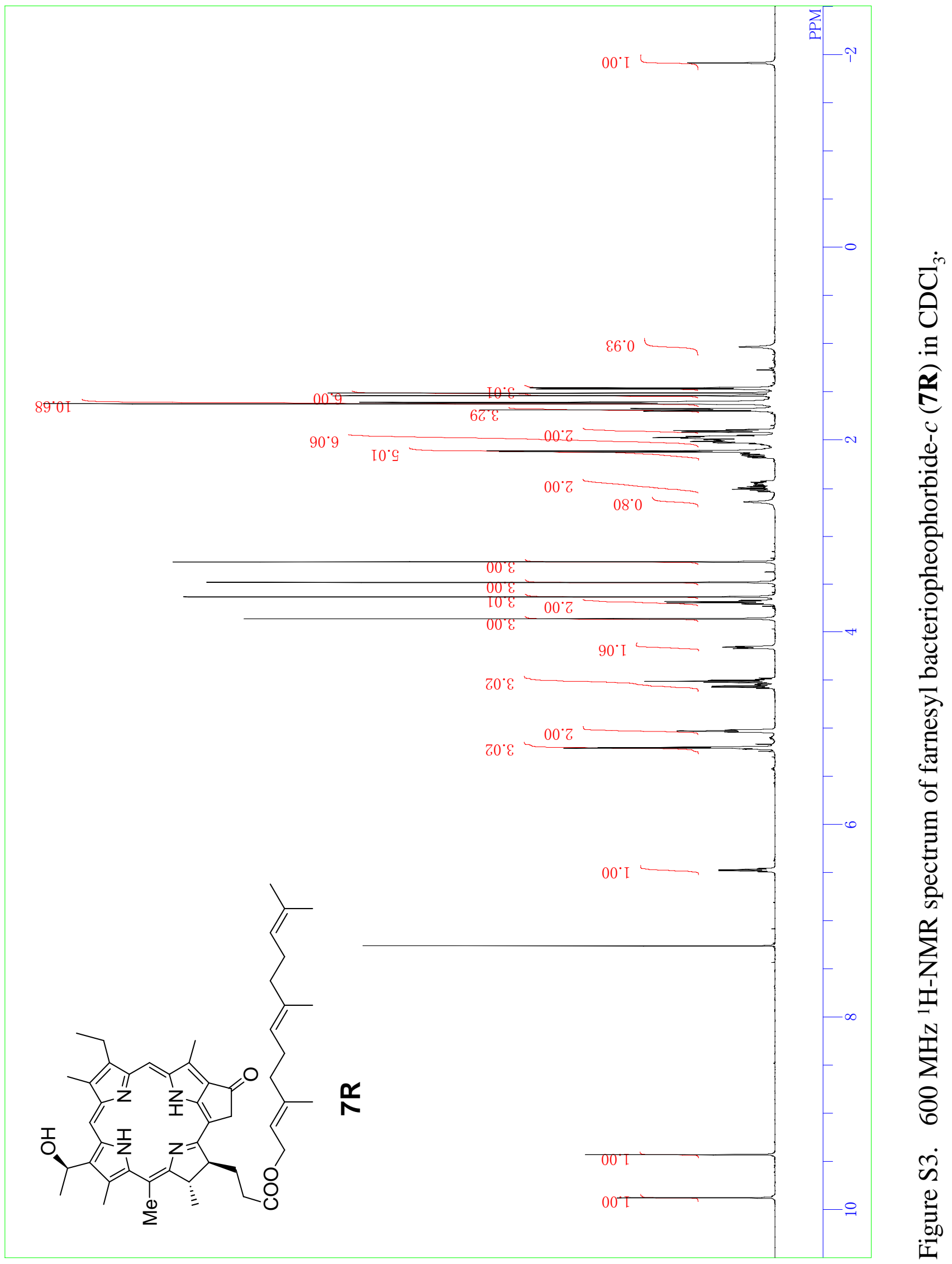


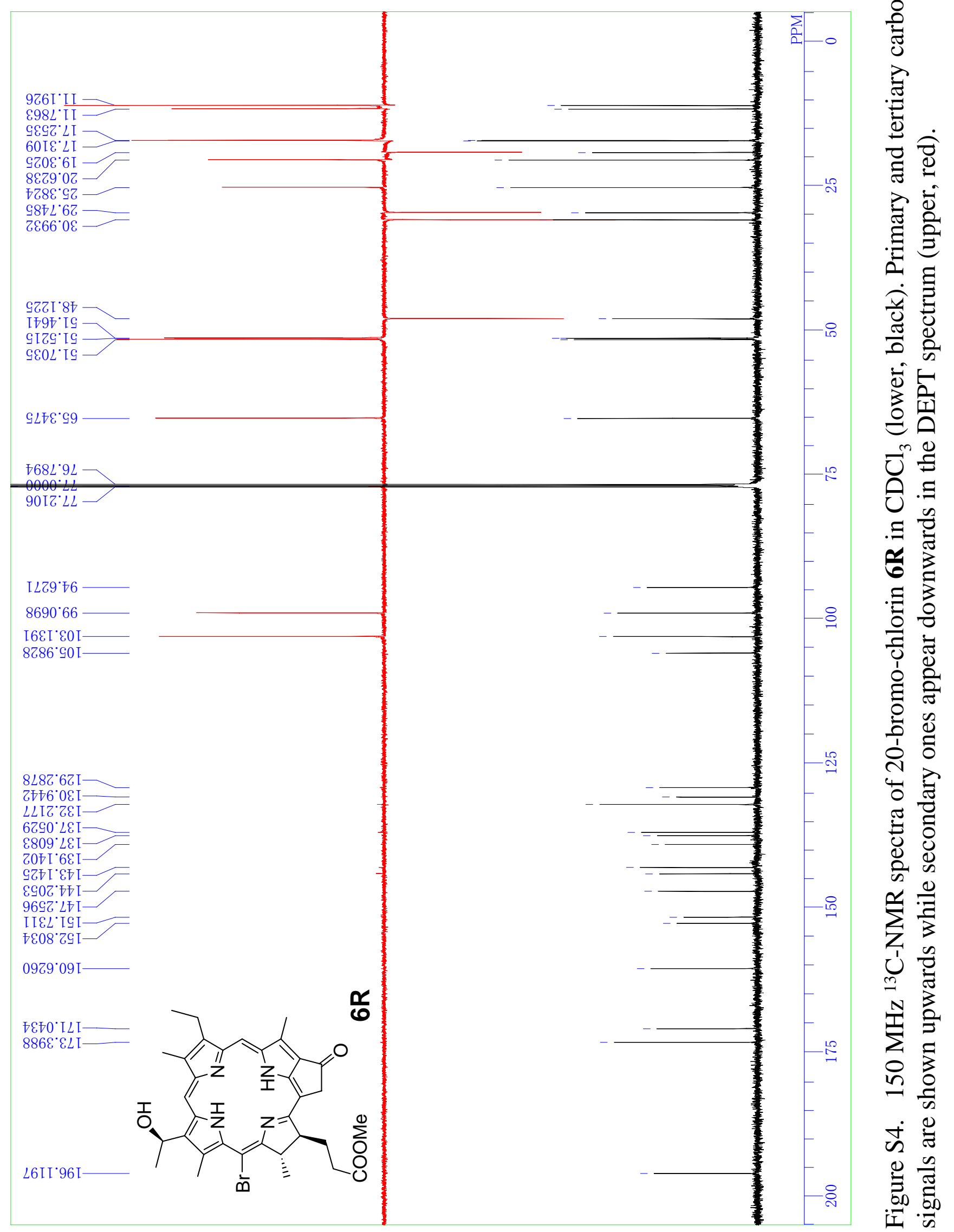




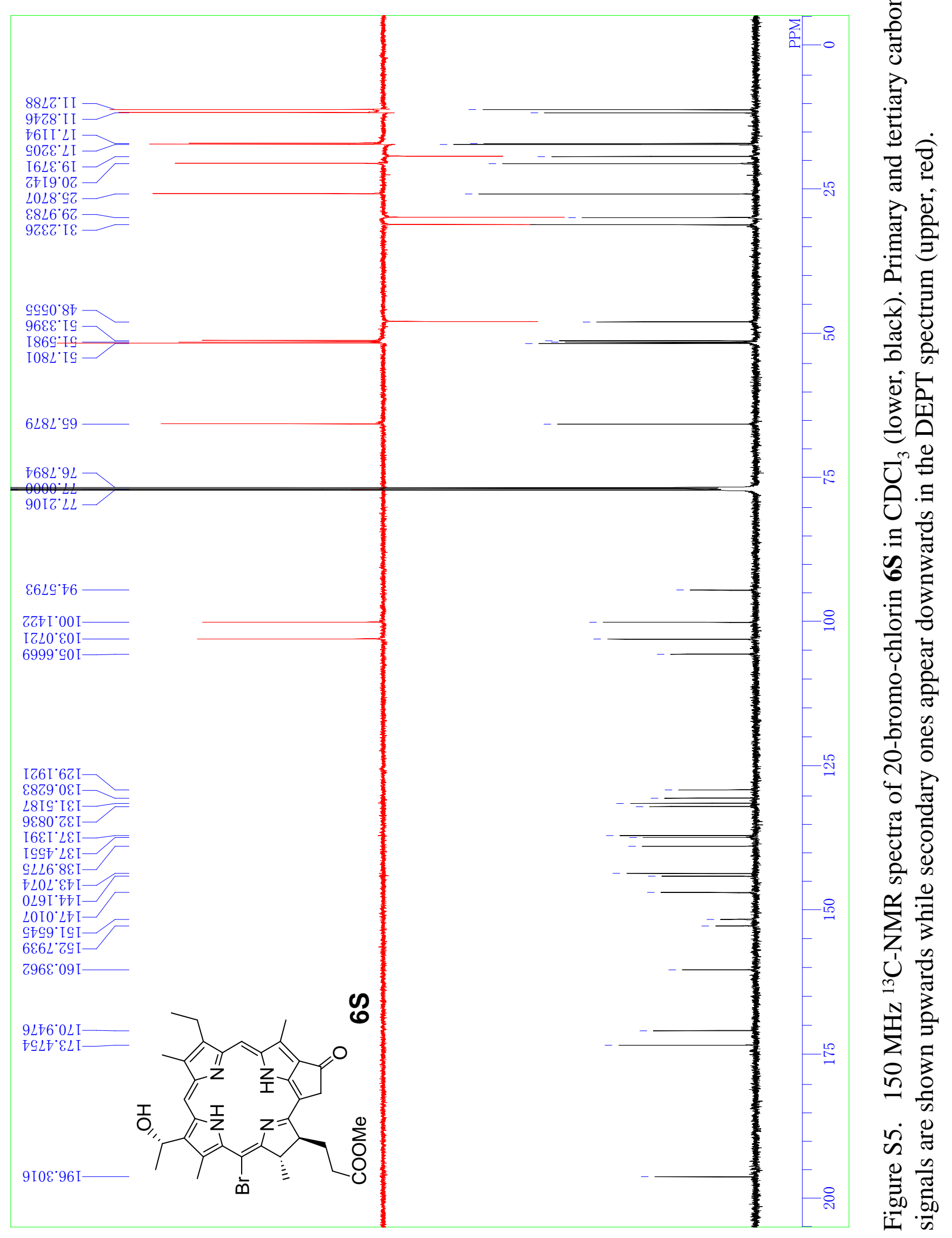




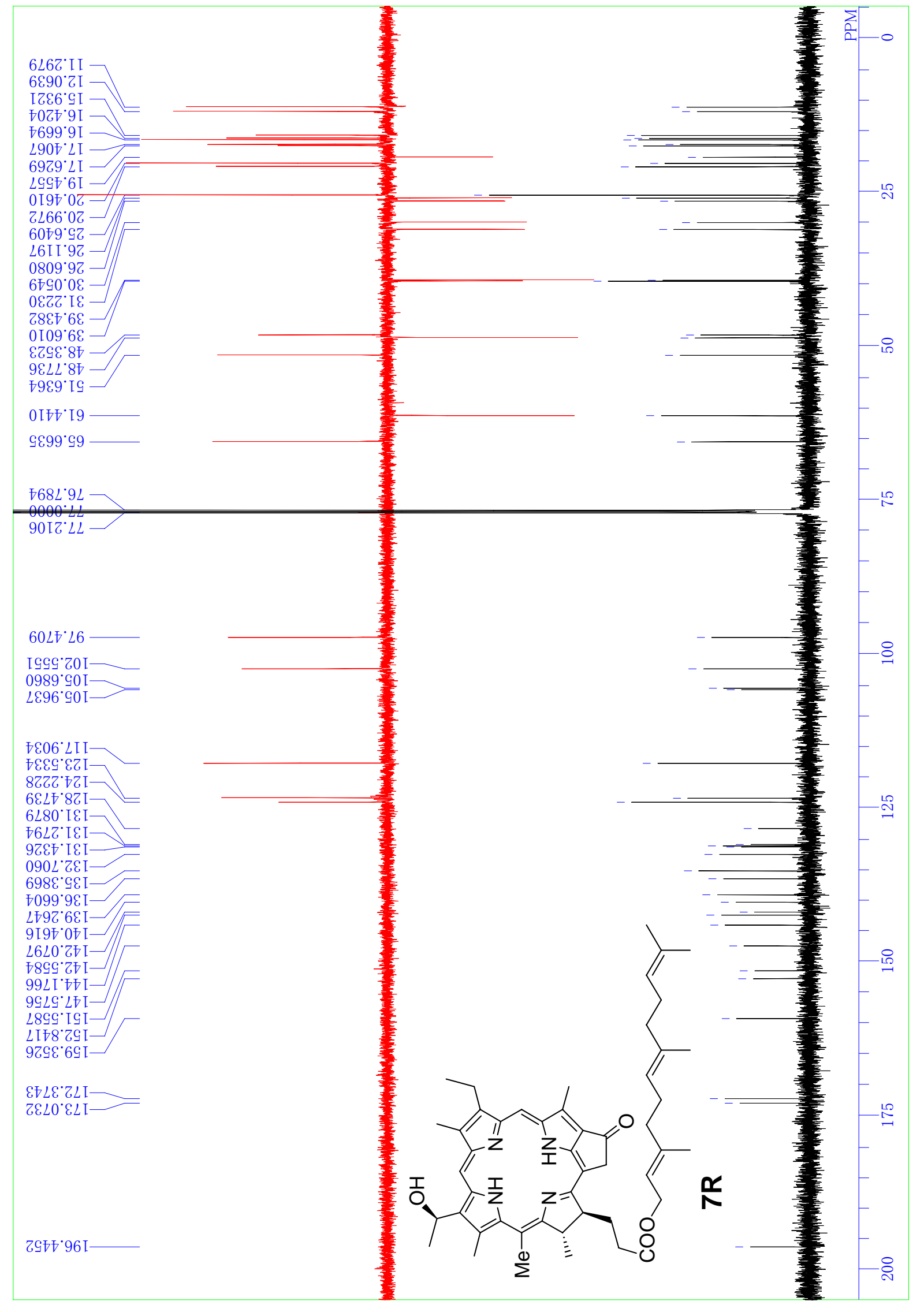

ซ్రి

當气

華

ลे ज

送望

$\rightarrow 0$

$\mathcal{2}$

$\cup$.

$\Xi \frac{0}{0}$

ช

N

¿

082.

90IZ.

60LF' $\angle 6$

[ $999^{\circ} \mathrm{ZO}[$

$0989^{\circ} 90 \mathrm{I} \longrightarrow$

7\&06.2I

จ\&\&9 \&6I

6EL7"8ZI

6L80. IE

$698 \varepsilon^{\circ} \mathrm{G} \varepsilon$

$7099^{\circ} 9 \varepsilon$

$\angle 620^{\circ} \mathrm{ZTI}$

$7899^{\circ}$ Z7 I

$289^{\circ}$ IG I-

LIt8.29 I

9796.69

EDLE'ZLI-

ZELO $E L I$

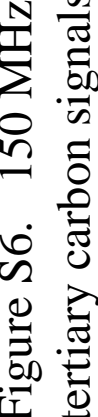

